\title{
Egressas de Ciência da Computação da Universidade Estadual do Oeste do Paraná: o que veio depois?
}

\author{
${ }^{1}$ Bianca Carvalho de Oliveira, ${ }^{1}$ Clodis Boscarioli, Eliane Nascimento Pereira ${ }^{2}$, \\ ${ }^{1}$ Gabriela Marim de Souza, ${ }^{1}$ Letícia Torres
}

${ }^{1}$ Ciência da Computação - Universidade Estadual do Oeste do Paraná (UNIOESTE) Cascavel- PR - Brasil

${ }^{2}$ Ciência da Computação - Universidade Estadual do Oeste do Paraná (UNIOESTE) Cascavel- PR - Brasil $\{$ bianca.c.o.bc, boscarioli, eliane.nascimentop, gabimarim06,
atorresleticia\}@gmail.com

\begin{abstract}
This paper presents a project in which the goal is to collect data about the female graduates of Computer Science of the Western Parana State University in order to comprehend what their challenges were during and after graduation. The research was applied through a form answered by 40 graduated out of a total of 102, and includes objective and open questions. After data collection, information was obtained, among others, about which were the graduate main areas of interest, as well if they suffered from prejudice and criticism. It was possible to establish ways to attract and motivate the permanence of women with interest in Computer area.
\end{abstract}

Resumo. É apresentado neste artigo a fase inicial de um projeto com o objetivo de coletar dados sobre as egressas do curso de Ciência da Computação da Universidade Estadual do Oeste do Paraná, a fim de compreender quais foram seus desafios durante e após a graduação. A pesquisa se deu por meio de um formulário (Google Forms), respondido por 40 egressas de um total de 102, e englobou questões objetivas e abertas. Após o levantamento de dados obteve-se informações sobre quais foram as principais áreas de interesse das egressas e se houve preconceito e críticas, dentre outras. Foi possível determinar formas de atrair e motivar a permanência de mulheres com interesse na área de Computação.

\section{Introdução}

É sabido que houve forte participação feminina na equipe que construiu o primeiro computador da história: seis mulheres foram designadas para ingressar no grupo de programação original do ENIAC [Goldstine 1980]. Muitas mulheres trabalharam também no começo da história da programação de computadores.

A partir da década de 80, no entanto, com a evolução dos computadores, a área passou a ser "coisa de menino" [Margolis and Fisher 2003]. Na época da construção do 
ENIAC, uma das selecionadas relatou que as mulheres não recebiam promoções apesar do grau de instrução, diploma de graduação ou título de doutorado. Era lhes dito que somente homens podiam conseguir cargos gerenciais. A mudança veio após a Segunda Guerra Mundial, quando a indisponibilidade de homens fez com que as mulheres fossem colocadas em cargos de supervisão [Fritz 1994]. Ainda hoje, no entanto, há relatos sobre discriminação entre cargos e salários entre homens e mulheres, embora, de acordo com a American Association of University Woman [AAUW 2017], as discrepâncias nas taxas gerais de remuneração entre homens e mulheres permaneceram estagnadas na última década.

Na década de 70 a primeira turma de bacharelado em Ciência da Computação do Instituto de Matemática e Estatística (IME) da Universidade de São Paulo (USP) tinha $70 \%$ de alunos do sexo feminino [Época Negócios 2015], talvez pelo fato desse curso ter surgido a partir da licenciatura em Matemática. No entanto, esse percentual de participação feminina nos cursos de graduação da área não se manteve, tendo, a partir da década de 90, começado a diminuir e hoje há uma minoria de mulheres nos cursos da área de computação no Brasil, sendo esta realidade também existente em outros países.

$\mathrm{Na}$ Universidad de los Andes, na Colômbia a participação feminina no curso de Engenharia de Sistemas e Computação tem diminuído. No início dos anos 90 a distribuição era de 65 homens e 35 mulheres. Dez anos após, o número de mulheres caiu para 10 [Casallas et al. 2012].

Essa baixa representação feminina [Galpin, 2002] se tornou preocupante, e muito se tem discutido sobre a atuação das mulheres tanto no meio acadêmico como na indústria. Para Nelson (2014), grupos com maior diversidade, seja de gênero, de educação, cultural ou experiência, são mais efetivos, pois produzem melhores resultados financeiros e inovadores.

Várias iniciativas vem sendo realizadas a fim de estimular mulheres e meninas a entrar na área de tecnologia, como as relatadas em [Lagesen 2017]. Há também programas criados também para esse fim, a exemplo do IEEE WIE (Women in Engineering) [IEEE-WIE 2017], uma iniciativa dedicada a promover a área das engenharias às mulheres, facilitando o ingresso e permanência dessas nas áreas técnicas em geral. No Brasil, há uma crescente de programas e projetos como essa mesma finalidade, como o RodAda Hacker ${ }^{1}$, Pyladies ${ }^{2}$ e o Minas Programam ${ }^{3}$, além do Meninas Digitais ${ }^{4}$ da Sociedade Brasileira de Computação (SBC).

A pouca participação das mulheres na área de Computação também é realidade nos cursos de Ciência da Computação da Universidade Estadual do Oeste do Paraná, dos campi de Cascavel e Foz do Iguaçu. Considerando esse panorama criou-se o projeto DIVAS (Descobrindo e Investigando o Valor e a Abrangência da participação feminina nas áreas computacionais) Digitais, a fim de coletar dados sobre as egressas com o objetivo de identificar os desafios que foram enfrentados durante e após a graduação e

\footnotetext{
${ }^{1} \mathrm{http}: / /$ rodadahacker.org

$2 \mathrm{http} / / /$ brasil.pyladies.com/

$3 \mathrm{http}: / /$ minasprogramam.com/

${ }^{4}$ Meninas .sbc.org.br/
} 
como se dá sua participação no mercado de trabalho, buscando, a partir das respostas das egressas, estratégias que possam contribuir no aumento da participação feminina na área, e motivar as mulheres que já possuem esse interesse.

\section{A pesquisa realizada}

Para a coleta de dados foi necessário buscar exaustivamente as egressas, pois o sistema da universidade não filtra os dados cadastrais dos egressos por sexo, além do problema dos dados desatualizados, uma vez que a universidade não possui controle de egressos. No campus de Cascavel, de 1993 a 2015, o número de egressas de Ciência da Computação totaliza 63, e no campus de Foz do Iguaçu, de 1995 a 2015 é de 39.

Houve dificuldade em adquirir os contatos atualizados. Houve, além do acesso aos dados do sistema acadêmico da universidade, o auxílio dos professores do curso e das próprias egressas, para atualização dos contatos, além de buscar as egressas em redes sociais. O questionário online, no Google Forms, foi distribuído às egressas em emails e via mensagem em seus perfis de redes sociais, previamente coletados.

O questionário foi elaborado com questões abertas e objetivas, abordando desde dados pessoais; anos de ingresso e término do curso; áreas de interesse; posição que ocupa no mercado; até o enfrentamento de preconceito, seja na universidade ou no trabalho. Algumas destas questões foram formuladas usando a Escala de Likert, em que as respostas especificam o nível de acordo ou desacordo com a questão, inserindo itens com escala simétrica [Burns and Bush 2012] Neste questionário a escala foi: (1) Concordo totalmente; (2) Concordo; (3) Indiferente; (4) Discordo; e, (5) Discordo totalmente. O questionário foi aplicado entre os meses de novembro e dezembro de 2016 e das 102 egressas, houve retorno de respostas de 40 .

\section{Análise dos Resultados}

Das respondentes, 52.5\% são do campus de Foz do Iguaçu e $47.5 \%$ de Cascavel. Observou-se que o maior número de ingressantes foi em 2000, com oito ingressantes; e o de egressas ocorreu nos anos de 2004 e 2005, ambos com sete egressas. Foi possível coletar alguns relatos sobre preconceito, críticas, expectativas e áreas de interesse.

Ao analisar as expectativas no ingresso do curso, percebeu-se que a maioria já tinha uma expectativa estabelecida. A mais recorrente foi sobre a atuação no mercado: desenvolver softwares, atuar na área científica, fazer concursos e ser bem sucedida. Houve também aquelas que ingressaram visando o aprimoramento de um conhecimento básico previamente obtido, curiosidade e aprendizagem a respeito de programação. Poucas dessas egressas não tinham conhecimento sobre a área e, portanto, não tinham expectativas claras; outras buscavam apenas um diploma de graduação com boa formação com corpo docente qualificado, ou tinham a intenção de ingressar, por afinidade, na área de Exatas.

A maioria das expectativas mudou. Dentre essas mudanças algumas foram positivas, como o surgimento do interesse em pós-graduação stricto sensu, desenvolvimento de pesquisa científica e mercado de trabalho. Em contrapartida, houve mudanças negativas, como decepção com as aulas práticas, com o mercado de trabalho 
e frustração com o nível de dificuldade do curso, acima do esperado.

Apesar da diversidade de expectativas, durante a graduação houve áreas que obtiveram maior interesse das egressas, dentre elas, as que predominam são Inteligência Artificial (10) e Engenharia de Software (12), seguidas por Algoritmos (5), Computação Gráfica (5) e Redes (3). Após a graduação, 26 dessas egressas seguiu atuando na área que mais lhe interessou; e uma baixa parcela (3) buscou outro curso de graduação.

Profissionalmente, 55\% das egressas atuam somente no mercado de trabalho, $27.5 \%$ seguiram somente na área acadêmica, $15 \%$ foram para outros ramos, e $2.5 \%$ atuam tanto no mercado quanto no meio acadêmico. Uma grande parcela concluiu algum tipo de pós-graduação, sendo $20 \%$ mestrado, $17.5 \%$ doutorado, e $42.5 \%$ especializações lato sensu diversas.

Ainda que houvesse interesse e vocação das egressas, algumas foram desmotivadas por críticas desconstrutivas. Embora muitas egressas não relataram preconceitos explícitos, ao analisar melhor algumas situações tornou-se perceptível a existência de algum tipo de preconceito. Por exemplo, no curso do campus Cascavel, já foram feitas apostas entre os homens sobre a permanência de mulheres que ingressaram no curso, como se não fossem capazes de concluí-lo, além da atenção reduzida que alguns professores dispensam às alunas quando em grupos de alunos de ambos os sexos.

Embora a maioria das egressas tenha relatado que não, para algumas a escolha do curso levou a críticas negativas, como o discurso de que "isso é curso de homem" e que "o curso é muito difícil". Na graduação uma minoria relatou que professores e alunos subestimaram suas capacidades de aprovação em alguma matéria.

A maior ocorrência de preconceitos foi após a graduação, no mercado de trabalho. O que se destacou foi a dúvida quanto à capacidade e competência das mulheres, piadas e comentários machistas por ser uma "área masculina", como "programar como homem", salários baixos e até assédio. Um relato que chamou a atenção foi o de uma Analista de Sistemas confundida como Secretária por um cliente.

A pouca participação de mulheres na Computação segundo a pesquisa se deve pela falta de informação e incentivo, falta de interesse e de a área ter o estigma de ser predominantemente masculina. Em meio a isso, como motivar as mulheres interessadas em Computação e incentivar sua permanência?

De acordo com as egressas, deve haver maior apoio dos professores às alunas, mostrar o mercado de trabalho e seus salários e ofertar palestras com mulheres bem sucedidas. Para aumentar a participação das mulheres houve as sugestões de: maior divulgação do curso em escolas, desenvolvimento de programas de incentivo, e dar maior destaque à participação feminina na área, que devem ser implementadas como sequência desse projeto.

\section{Conclusões}

A pesquisa possibilitou conhecer um pouco a realidade das egressas da área de Computação da Universidade Estadual do Oeste do Paraná. Pode-se certificar que ainda é preciso encontrar formas de motivar mulheres que já possuem interesse na área, e, 
mais, criar meios para divulgar a Computação às que não a conhecem, o que pode acarretar em manifestação de interesse. Além disso, há que lhes mostrar que para quebrar o preconceito e as críticas ruins que ainda existem, elas devem se posicionar firmemente durante e após a graduação, insistindo na área para a qual tem vocação.

Como continuidade deste projeto vislumbram-se ações de acompanhamento das alunas no curso, bem como a implementação de ações de divulgação já citadas, buscando também um esforço conjunto com outras sociedades representativas de áreas das Ciências Exatas, para melhor esclarecer os objetivos e o perfil do egresso de cursos da área da Ciência da Computação, desmistificando que é uma área masculina.

Ainda como trabalhos futuros pode-se citar a aplicação de questionário sobre a atuação após a graduação aos egressos, de forma a comparar as realidades de vivências experimentadas pelos homens com as descritas pelas egressas nessa pesquisa. Ainda, comparar os resultados, dentro do que for possível, com pesquisas correlatas.

\section{Referências}

AAUW (2017). The Simple Truth about Gender Pay Gap. Spring 2017 Edition. Technical Report. Disponível em: www.aauw.org/research/the-simple-truth-aboutthe-gender-pay-gap/ Acessado em: 03 de maio de 2017.

Burns, A., Bush, R. (2012). Marketing Research (7 ed). New Jersey: Pearson Education.

Casallas, R., Rodríguez, D. H., Hernández, J. T., Ortega, M. F. (2012). Understanding the women participation decline in systems \& computing engineering: Case study at the university of los andes, Colombia. In: XXXVIII Conferencia Latinoamericana En Informatica (CLEI), p. 1-6.

Época Negócios (2015). Por que há menos mulheres no setor de tecnologia? http://epocanegocios.globo.com/Informacao/Dilemas/noticia/2015/08/por-que-hamenos-mulheres-no-setor-de-tecnologia.html. Acessado em: 14 de março de 2017.

Fritz, W. B. (1994). Eniac - A Problem Solver. IEEE Annals of the History of Computing, 16(1):25-45.

Galpin, V. (2002). Women in computing around the world. ACM SIGCSE Bulletin Women and Computing, New York, USA, 34(2):94-100.

Goldstine, H. H. (1980). The computer from Pascal to von Neumann. Princeton University Press.

IEEE-WIE (2017). IEEE Women in Engineering (WIE). Disponível em http://www.ieee.org/membership_services/membership/women/women_about.html Acessado em: 13 de março de 2017.

Lagensen, V. A. (2017). The Strength Numbers: Strategies to Include Women into Computer Science. In: Social Studies of Science, 37(1):67-92.

Margolis, J. and Fisher, A. (2003). Unlocking the clubhouse: Women in computing. MIT press.

Nelson, B. (2014). The data on diversity. Communications of the ACM, 57(11):86-95 